University of Warwick institutional repository: http://go.warwick.ac.uk/wrap This paper is made available online in accordance with publisher policies. Please scroll down to view the document itself. Please refer to the repository record for this item and our policy information available from the repository home page for further information.

To see the final version of this paper please visit the publisher's website. Access to the published version may require a subscription.

Author(s): Dan Anderberg and Carlo Perroni

Article Title: Time-Consistent Policy and Politics: Does Voting Matter When Individuals Are Identical?

Year of publication: 2003

Link to published version:

http://dx.doi.org/http://dx.doi.org/10.2202/1538-0653.1101

Publisher statement: None 


\section{Topics in Economic Analysis \& Policy}

Volume 3, Issue 1

2003

Article 3

\section{Time-Consistent Policy and Politics: Does Voting Matter When Individuals Are Identical?}

\author{
Dan Anderberg*
}

\author{
Carlo Perroni ${ }^{\dagger}$
}

*University of Stirling, Dan.Anderberg@stir.ac.uk

†University of Warwick, c.perroni@warwick.ac.uk

Copyright (C) 2003 by the authors. All rights reserved. No part of this publication may be reproduced, stored in a retrieval system, or transmitted, in any form or by any means, electronic, mechanical, photocopying, recording, or otherwise, without the prior written permission of the publisher, bepress, which has been given certain exclusive rights by the author. Topics in Economic Analysis \& Policy is produced by The Berkeley Electronic Press (bepress). http://www.bepress.com/bejeap 


\title{
Time-Consistent Policy and Politics: Does Voting Matter When Individuals Are Identical?
}

\author{
Dan Anderberg and Carlo Perroni
}

\begin{abstract}
We consider the implications of a lack of policy commitment when policies are chosen through a political process and individuals are ex-ante identical. We show that politics, by allowing expost distributional tensions to shape policy, can make it possible to sustain non-trivial equilibria in which the commitment problem is alleviated or fully eliminated. How effective politics can be at countering collective commitment problems in homogeneous groups depends on the nature of the political process and on the extent to which private choices are public information.
\end{abstract}

KEYWORDS: Time-Consistent Policy, Voting, Taxation 


\section{Introduction}

A vast literature, initiated by Kydland and Prescott (1977) and others, has documented that equilibrium outcomes in dynamic environments can be extremely inefficient when policy makers cannot commit to policy. The literature has pointed out numerous potential credibility problems, with applications ranging from capital taxation and education policies to tax evasion and criminal sanctions. $^{1}$

Much of this literature abstracts from political mechanisms of policy formation. Implicit in this omission is the idea that, if one can abstract from population heterogeneity, then how policy choices are made is largely immaterial: any collective choice procedure that respects the Pareto criterion should produce the same outcome as that which obtains from a benevolent planner's maximization of a representative agent's welfare.

This paper shows this line of argument to be deceptive; the reason is that, even in the absence of population heterogeneity, if ex-ante identical individuals engage in different actions, the resulting ex-post heterogeneity can give rise to redistribution through the political process. Then, if sufficiently powerful policy instruments are available, it can become rational for an individual to conform with the choices of others, so as to be in the group that benefits from redistribution at the ex-post stage.

It is thus important to recognize that ex-ante homogenous individuals do not necessarily remain homogeneous, even along an equilibrium path; as a result non-trivial equilibria can, through political incentives, obtain, in which credibility problems are alleviated or even fully eliminated. The implication of this result is then that, when characterizing time-consistent policies in large economies, even if one elects to abstract from population heterogeneity, one cannot abstract from politics; doing so can significantly bias conclusions.

The idea that individuals do not have to be different in order for politics to shape time-consistent policies has been overlooked in the literature. There is a literature on the implications of politics for policy credibility, ${ }^{2}$ but, in all

\footnotetext{
${ }^{1}$ One of the earliest contributions to the literature on time-consistent capital taxation is Fischer (1980), who analyzed a general two-period version of the capital-levy problem where policy is chosen by a benevolent planner. The literature on time-consistent education policies is more recent, and includes, e.g., Boadway, Marceau, and Marchand (1996a), and Konrad (2001). Boadway, Marceau, and Marchand (1996b), and Boadway and Keen (1998) look at policy credibility problems in the context of criminal sanctions and tax enforcement respectively.

${ }^{2}$ One of the most influential ideas in that literature is that of strategic delegation (see e.g. Persson and Tabellini (1994)). If policy is selected, after the agents make their private choices, by a policy-maker who is appointed prior to those private choices, then, when voting over the identity of the policy-maker, voters will elect a non-median candidate who has expost incentives to select a policy which is close to that favoured by the median voter from an ex-ante perspective. This mechanism relies on the presence of ex-ante heterogeneity, as well as on elections being held prior to the agents choosing actions: in this sense it does rely on commitment - not to policy, but to the identity of the future policy-maker. More recent contributions, which also rely on the presence of ex-ante heterogeneity, are Gradstein $(1999 \mathrm{a}, \mathrm{b})$. Gradstein (1999b) shows, using a version of the capital-levy problem, that if it is possible to commit, at the ex-ante stage, to the democratic rule to be applied at the ex-
} 
of those contributions, politics matter only insofar as individuals are different ex ante. In the mechanism we describe, politics do not affect equilibrium policy outcomes because of the way ex-ante differences are reconciled by a certain political process; rather, it is the very presence of a political process of policy formation that generates heterogeneity, making possible an equilibrium combination of policies and private choices that would not otherwise be sustainable. ${ }^{3}$

We first briefly illustrate this argument by applying it to a familiar capitallevy problem (Section 2), in a model where distortionary labour and capital taxes are selected by majority voting and investment choices are fully observable. We demonstrate that "reasonably good" subgame-perfect equilibria may exist in this case, where capital income is not fully taxed and a majority of individuals select a high level of investment.

The capital-levy problem, while useful for illustrating our general point, is not ideal for exploring the above mechanism more fully. The reason is that the problem exists in this case only because of an exogenous constraint on the structure of that instruments that can be used for ex-post redistribution. It could be argued, however, that a majority has broader discretion in designing policy instruments; the only relevant constraints should be those that stem directly from an inability to observe private choices (and thus to condition policies on them). Allowing for such endogeneity in the choice of policy instruments, in dependence of the amount of information that is publicly available, allows us to illustrates our second main point: that public information about private choices generally has a positive value in the sense that it can help support more efficient equilibria.

To this end, we present, in Section 3, a second application. We consider a social insurance problem where risk-averse individuals face idiosyncratic earnings risk; the probability of favourable earnings outcomes can be increased by means of private costly investments in education. After education choices have been completed, a social insurance scheme (a redistributive tax scheme) must be agreed upon before earnings uncertainty is resolved. In this model, the provision of social insurance runs against a moral-hazard problem, which gives rise to a policy credibility problem: from an ex ante point of view, in order to generate incentives to invest in education, less than full insurance should be provided. However, this would imply ex-post inefficient risk-sharing. In contrast to the capital-levy problem, in this application the set of available policies is constrained only by information. Moreover, the mapping from private choices to earnings outcomes is stochastic, generating a standard inference problem.

We show that the more public information is available about private choices, the more private effort can, in general, be supported. As a consequence, the indi-

policy choice stage, efficiency can be enhanced by stipulating that tax changes must garner the support by a super-majority. Gradstein (1999a) considers the value of public education when there is ex-post voting over taxes.

${ }^{3}$ A related mechanism has been described by Fudenberg and Tirole (1990) for the case of renegotiation in a standard moral-hazard/principal-agent. What they show is that the possibility of renegotiation can give rise to an endogenous adverse selection problem by inducing the agent to randomize over actions. 
viduals have a common incentive to invest in a public information infrastructure prior to making the private decisions. This result on the value of information is in stark contrast with the conclusion we would reach if, absent heterogeneity, we assumed politics away: then, we would conclude that more information might very well lead to more inefficient outcomes.

Proofs of results (unless outlined in the text) are provided in an appendix.

\section{Time-Consistent Capital Taxation under Ma- jority Voting}

Consider an economy with a continuum of ex-ante identical individuals living for two periods. All individuals have an endowment of one unit of consumption in the first period and one unit of time in the second period. Each agent chooses savings, $k$, in the first period, and labour supply, $l$, in the second period. We shall assume that there are only two feasible levels for $k$ : an agent can either "spend" or "invest", $k \in\{0,1\}$. For simplicity, we assume separable and quasilinear preferences over first- and second-period consumption, $c_{1}$ and $c_{2}$, and second-period leisure, $z_{2}$ :

$$
u\left(c_{1}, c_{2}, z_{2}\right) \equiv c_{1}+\frac{1}{(1+\beta)}\left(c_{2}+f\left(z_{2}\right)\right),
$$

where $f$ is increasing and concave, and where $\beta \geq 0$ represents the rate of time preference. Denote the net return to investment by $r>0$ and the wage rate by $w$. In the second period the government must collect a revenue $G$ per capita through a proportional tax on interest income, $\tau_{K} \in[0,1]$, and a proportional tax on labour income, $\tau_{L} \in[0,1]$. Then $c_{1}=1-k, c_{2}=$ $k\left[1+\left(1-\tau_{K}\right) r\right]+\left(1-\tau_{L}\right) w l$, and $z_{2}=1-l$.

Given the above preferences, whether an agent invests $(k=1)$ or does not $(k=0)$ only depends the net-of-tax return to investment. Let $\widetilde{\tau}_{K} \equiv 1-\beta / r$; an individual will strictly prefer to "invest" (alt. "spend") if $\tau_{K}<\widetilde{\tau}_{K}$ (alt. $\left.\tau_{K}>\widetilde{\tau}_{K}\right)$, and will be indifferent between the two actions when equality holds. We shall assume $r>\beta$; hence saving is the efficient action and $\widetilde{\tau}_{K}>0$.

Similarly, labour supply depends only on the net-of-tax wage. A worker chooses $l$ so as to maximize the net income from labour income, less the disutility of labour; thus define

$$
v\left(\tau_{L}\right) \equiv \max _{l}\left(\left(1-\tau_{L}\right) w l+f(1-l)\right)
$$

as the net indirect utility from labour. The associated first-order condition, $\left(1-\tau_{L}\right) w=f^{\prime}(1-l)$, implicitly defines labour supply as a function of the tax on labour income, $l\left(\tau_{L}\right)$. We shall assume that the elasticity of labour supply with respect to the labour income tax, $\varepsilon_{l \tau_{L}} \equiv l^{\prime}\left(\tau_{L}\right) \tau_{L} / l\left(\tau_{L}\right) \leq 0$ is monotonically decreasing in $\tau_{L}$.

A capital tax $\tau_{K}>\widetilde{\tau}_{K}$ drives investment to zero and is therefore distortionary, but the deadweight loss it produces is independent of the level of $\tau_{K}$. 
Labour taxation is also distortionary in this model; in this case, however, the associated deadweight loss is increasing in $\tau_{L}$. We shall assume that $\widetilde{\tau}_{K} r<G<r$; the second inequality implies that a one-hundred percent tax on interest income would be enough to meet the revenue requirement if all individuals save; however, the first inequality implies that the required tax would exceed $\widetilde{\tau}_{K}$. This means that, since capital tax revenues are zero for any $\tau_{K}>\widetilde{\tau}_{K}$, a distortionary labour tax must also be used alongside a nondistortionary capital tax. If policy commitment were possible, the optimal tax structure would then have a very simple structure: the capital tax would be set at the highest non-distortionary level, i.e. $\widetilde{\tau}_{K}$, and labour taxes would be used residually to meet the revenue requirement.

Suppose now that policy commitment is not feasible. Specifically, consider a sequential game where, first, agents make investment decisions; then, a tax policy is determined by majority voting; finally, agents make labour supply decisions. The game trivially has a pure-strategy subgame-perfect equilibrium in which no agent invests. ${ }^{4}$ On the other hand, no pure-strategy equilibrium in which all agents invest can be sustained: if all agents invested, then, at the ex-post stage, capital income would be fixed, and all agents would unanimously agree to fund $G$ first by capital taxes; hence the capital tax would be $\tau_{K}=$ $G / r>\widetilde{\tau}_{K}$, which contradicts that agents would rationally invest.

This still leaves open the possibility of asymmetric equilibria where a fraction $\theta \in(0,1)$ of the population choose to invest - or, equivalently, mixed-strategy equilibria where each agent chooses to invest with probability $\theta .{ }^{5}$ Such an equilibrium requires that agents be indifferent between spending and investing, i.e. it must involve $\tau_{k}=\widetilde{\tau}_{K}$. This cannot occur if the interim majority consists of "spenders" $(\theta<1 / 2)$. Since spenders have no capital income, their continuation utility is simply $v\left(\tau_{L}\right)$. Therefore, their ideal policy would involve taxing capital income first, implying $\tau_{K}=\min \{1, G /(r \theta)\}$; labour income taxes would, if necessary, be residually determined. Hence, if $\theta<1 / 2$, the political process would select a capital tax $\tau>\widetilde{\tau}_{K}$. Hence we can rule out mixed-strategy equilibria with $\theta \in(0,1 / 2)$.

This leaves one possible scenario: the "investors" may be in majority in the interim $(\theta>1 / 2)$. At the ex-post stage, investors face a trade-off between efficiency and redistribution: since the capital tax base is fixed ex post, capital income taxation generates no deadweight loss whereas labour taxation does; however, taxing capital has an adverse redistributive effect on the investors themselves. Their ideal policy is that which maximizes their continuation utility $1+\left(1-\tau_{K}\right) r+v\left(\tau_{L}\right)$, subject to the revenue requirement $\tau_{L} w l\left(\tau_{L}\right)+\theta \tau_{K} r \geq$ $G$. This yields the necessary condition $1+\varepsilon_{l \tau_{L}}=\theta$, which implicitly defines

\footnotetext{
${ }^{4}$ If all agents spend in the first period, there is no capital to tax in the second period. Hence any $\tau_{K}$ is optimal; any $\tau_{K}>\widetilde{\tau}_{K}$ supports an equilibrium. Perfecting the equilibrium (see Section 3 below) gives $\tau_{K}=1$. Alternatively, one could augment the model by assuming that there is some exogenous capital income in the second period in addition to that generated by endogenous investment; then, a choice $\tau_{K}=1$ would be an actual equilibrium strategy.

${ }^{5}$ For the sake of brevity, we shall hereafter refer to such outcomes simply as mixed-strategy equilibria.
} 
a monotonically decreasing relationship, $\tau_{L}(\theta)$, between the investors' ideal labour tax and $\theta . \tau_{L}(\theta)>0$ for all $\theta<1$ but approaches zero as $\theta$ approaches unity. The investors' ideal capital tax is determined residually as

$$
\tau_{K}(\theta) \equiv \frac{G-\tau_{L}(\theta) w l\left(\tau_{L}(\theta)\right)}{\theta r} .
$$

Note that $\tau_{K}(\theta)$ approaches $G / r$ as $\theta$ approaches unity.

Consider then how $\tau_{K}(\theta)$ changes as we lower $\theta$ from unity. On the one hand, labour taxation rises from zero, reducing the residual revenue to be raised through capital taxes; on the other hand, there is less capital income to tax. Provided that $\varepsilon_{l \tau_{L}}$ does not respond too sharply with the introduction of labour taxation, the first effect dominates, and $\tau_{K}(\theta)$ will be less than $G / r$ (and keep decreasing over some interval as $\theta$ is further decreased towards $\theta=1 / 2$ ). Then, if there is a $\theta^{\prime}>1 / 2$ such that $\tau_{K}\left(\theta^{\prime}\right)=\widetilde{\tau}_{K}$, a mixed-strategy equilibrium where a majority of agents invest can be supported.

Figure 1 shows what happens as $G$ is increased from the critical revenue requirement $\bar{G} \equiv \widetilde{\tau}_{K} r=r-\beta$ (the largest revenue that can be raised by nondistortionary capital income taxes alone). As $G$ is increased to $G^{\prime}>\bar{G}$, it is no longer possible to sustain an equilibrium with $\theta=1$. However, a new mixedstrategy equilibrium with $\theta=\theta^{\prime}$, close to unity, appears. If everyone saves with probability $\theta^{\prime}$, then, ex post, investors are in majority, and will optimally vote for the capital tax $\tau_{K}\left(\theta^{\prime}\right)=\widetilde{\tau}_{K}$, which, when rationally expected, makes everyone indifferent between investing and spending, and hence willing to randomize.

Such a mixed-strategy equilibrium is not fully efficient, but it dominates the pure-strategy equilibrium with $\theta=0$, as it features a lower labour tax rate hence a lower deadweight loss from labour taxation - and higher investment - hence a lower deadweight loss from capital taxation. Thus, a "nearly efficient" outcome can still be supported if tax policies are selected by majority voting, although very inefficient outcomes, where capital income would face a one-hundred percent tax, are still possible. Yet, if we abstracted from voting on the grounds that agents are ex-ante identical, we would reach the conclusion that the full taxation of capital is the only time-consistent equilibrium policy.

The extent to which politics can help overcome policy credibility problems depends on the specific characteristics of the political process. To see this, consider, as an example, a simple version of electoral uncertainty and "ideology" (Lindbeck and Weibull, 1987; Dixit and Londregan, 1998, Persson and Tabellini, 2000). As in our preceding discussion, we consider a sequence where elections are held after the agents choose investment. Suppose that there are two political candidates, $A$ and $B$, each purely office-motivated and able to commit to a platform $\left(\tau_{K}^{j}, \tau_{L}^{j}\right), j \in\{A, B\}$, prior to elections. Candidates differ along some dimension which is unrelated to tax policy but which affects how agents rank them; agents, however, only learn about candidates' characteristics after making their investment decisions and after candidates have committed to a certain tax policy platform. This can be modelled by making an agent's continuation utility depend on a candidate's type through additive taste shocks, both individualspecific $\left(\sigma^{i}\right)$ and economy-wide $(\delta)$, that are independently and unimodally dis- 


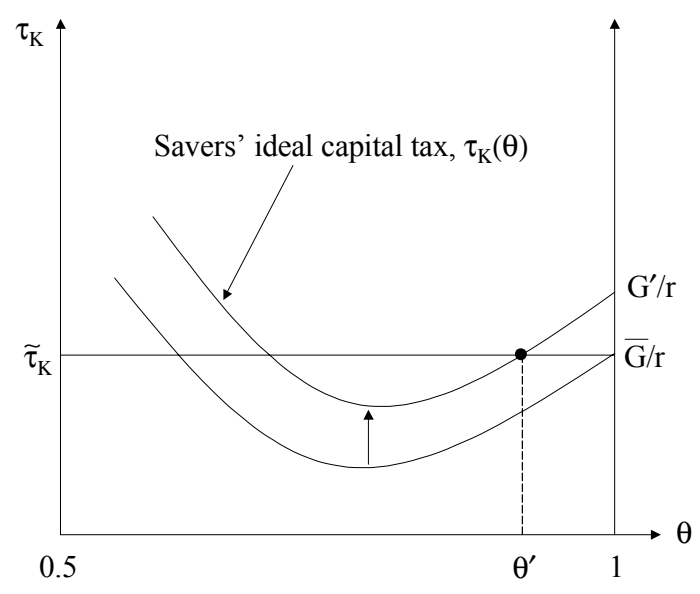

Figure 1: Mixed-strategy equilibrium in the capital-levy problem.

tributed and are revealed to agents after investment choices have been made and policy platforms have been chosen. Then, whether an agent votes for candidate $A$ or candidate $B$ will depend on each candidate's announced policy as well as on the taste shocks: an agent $i$ who has not invested in the first period will vote for $A$ if and only if $v\left(\tau_{L}^{A}\right)>v\left(\tau_{L}^{B}\right)+\sigma^{i}+\delta$; and an agent $i$ who has invested will vote for $A$ if and only if $\left(1-\tau_{K}^{A}\right) r+v\left(\tau_{L}^{A}\right)>\left(1-\tau_{K}^{B}\right) r+v\left(\tau_{L}^{B}\right)+\sigma^{i}+\delta$.

In this scenario, each candidate will choose the tax policy platform that maximizes the probability of electoral success, given the policy announced by the other candidate, and given $\theta$. It can be shown that, when the $\sigma_{i}$ s are identically distributed, in a symmetric equilibrium, each candidate chooses the platform that maximizes the sum of the continuation utilities of all the agents in the economy; in other words, this political process implies that the interim utilitarian optimum will be implemented. This leads to capital being taxed first, i.e. $\tau_{K}=\min \{1, G /(\theta r)\}>\widetilde{\tau}_{K}$. But this removes investment incentives: in the unique equilibrium no one invests. The problem here is that the electoral uncertainty moderates the policy: the political process does not strongly privilege the majority, and hence weakens the tendency to conformity.

How effective politics can be at sustaining non-trivial policy equilibria in homogeneous groups also depends on the extent to which policies can favour the majority at the expense of the minority. This, in turn, depends on which policy tools are available. In the capital-levy example, the limited set of tax instruments at the majority's disposal limits their ability to redistribute, and therefore reduces the pressure toward conformity which makes high-investment outcomes possible. ${ }^{6}$ However, more generally, the set of available policy tools

${ }^{6}$ If, for example, a majority consisting of investors $(\theta>1 / 2)$ can levy a labour income 
should depend on what information is available about private choices. This raises the question if more information is generally a good thing. In order to consider this we turn to a second application.

\section{Education, Social Insurance, and Information}

Our second application which is chosen to highlight the positive role played by information involves a moral-hazard problem stemming from redistributive taxation. We shall describe a model where individuals face idiosyncratic earnings risk, and where the probability of unfavourable earnings outcomes can be reduced by costly private investment in education (the ex-ante stage). After private education choices have been made, there is still scope for social risk pooling, which can be realized through a system of redistributive taxes (social insurance, chosen at the ex-post stage). In this scenario, unless a system of redistributive taxes can be committed to at the ex-ante stage, incentives on education choices will be disregarded by ex-post risk sharing decisions.

\subsection{Education and Earnings Insurance}

In the first period each agent chooses an education level or "effort" level $h \in$ $\left\{h^{1}, h^{2}\right\}$, where $h^{2}>h^{1}$. In the second period the agents work, inelastically supplying one unit of labour. Earnings in the second period are a random variable $w \in\left\{w_{1}, w_{2}\right\}$, with $w_{2}>w_{1}$, whose probability distribution is independent across consumers but is conditional on first-period effort. Specifically, denoting the probability of $w_{i}$ given effort $h^{k}$ by $\pi_{i}^{k} \in(0,1), i, k=1,2$, we shall assume that $\pi_{2}^{2}>\pi_{2}^{1}$, i.e. a higher level of first-period effort raises the probability of experiencing earnings $w_{2}$. Agents derive utility from consumption and disutility from effort: given consumption $c$ and effort $h^{k}$, an agent obtains utility $u(c)-g^{k}$, where $u$ is increasing and concave, and where $g^{k}$ denotes the utility cost of effort $h^{k}$. We shall assume that the high effort is more costly $-g^{2}>g^{1}-$ but efficient under perfect risk-sharing $-\sum_{i}\left(\pi_{i}^{2}-\pi_{i}^{1}\right) w_{i}>g^{2}-g^{1}$. Henceforth, an agent's "type" in the second period will refer to her first-period effort choice, i.e. a type- $k$ agent is an agent who has exerted effort $h^{k}, k=1,2$.

Social pooling of income risk is realized in practice through redistributive taxes and transfers; for the purpose of our analysis, however, it is convenient to model social insurance directly in terms of state-contingent consumption levels. Under such a scheme, consumption can be conditioned on earnings, which are assumed to be fully observable, as well as on any other observable signals that are received ex post along with earnings realizations, and which may be correlated with effort.

Such auxiliary information will be modelled as generally as possible, relying

surtax to be paid exclusively by non-investors, then an efficient outcome with $\theta=1$ may be sustainable: all individuals would choose to invest even if $\tau_{K}>\tilde{\tau}_{K}$ in order to avoid incurring the labour income surtax - a redistributive instrument which the majority would rationally choose to exploit ex post. 
on the notion of signal structure, which associates a probability to a certain signal being sent by an agent of a certain type. A signal structure $\sigma$ thus consists of a combination of a finite signal space, $S$, and a probability distribution, $f$, over signals, where $f_{j}^{k}$ represents the probability that a type- $k$ agent sends the signal $s_{j} \in S$. We shall also use the notation $S^{k}$ to denote the support of the signal distribution given effort $h^{k}$-i.e. the smallest subset of $S$ that has probability one given effort $h^{k}$. The signal structure $\sigma \equiv(S, f)$ can be thought of as being exogenous, or, alternatively, as being the result of a costly investment in collective infrastructure (see below).

Given the above definitions, an insurance contract, $C$, can then be described as a mapping assigning a consumption level $c_{i j}$ to each possible earnings/signal combination $\left(w_{i}, s_{j}\right)$. In principle, more than one contract may be offered as part of a social insurance scheme, with each agent having a choice amongst contracts; a social insurance system can thus generally be described as a menu of contracts. Since the social insurance system is put in place before any signals or earnings outcomes are realized - when agents are indistinguishable from each other we shall impose a basic anonymity requirement: all agents must be offered the same menu of contracts. Also, in order to be feasible, a social insurance system must satisfy an aggregate resource constraint. Since the economy is large and all risk is idiosyncratic, there is no aggregate uncertainty; therefore, we can simply require that the economy's resource constraint must hold in expectations. Using $\bar{w}^{k} \equiv \sum_{i} \pi_{i}^{k} w_{i}$ to denote the expected income for a type- $k$ agent, $\theta^{k}$ to denote the probability that an agent chooses effort $h^{k}$ in a symmetric outcome, and $C^{k}$ to denote the contract chosen by type- $k$ agents (from the available menu of contracts), the resource constraint can be expressed as

$$
\sum_{k} \theta^{k}\left(\bar{w}^{k}-\sum_{j} \sum_{i} f_{j}^{k} \pi_{i}^{k} c_{i j}^{k}\right) \geq 0
$$

\subsection{Policy Preferences and Voting}

We restrict our attention to a scenario where decisions on social insurance at the ex-post stage - i.e. after education choices - are taken by majority voting. At that stage, there can only be two voter types, low-effort individuals and higheffort individuals. Then, each agent can do no better than to vote for the menu of insurance contracts that maximizes her type's continuation utility, given the distribution of types in the economy; consequently no menu of contracts can defeat the menu that is optimal from the point of view of the interim majority type. $^{7}$

Given that there are at most two ex-post types, we can, without loss of generality, restrict the number of contracts in a menu to two. Hence, assume that each agent votes for a menu consisting of one contract, $C^{k k}$, intended for

\footnotetext{
${ }^{7}$ With two voter types, a majoritarian outcome is consistent with a broad class of political mechanisms. A benefit of using more realistic models of the political process, such as citizencandidate models, would be that they can better handle generalizations to more than two available actions (owing to the fact that they have better equilibrium existence properties).
} 
her own type, and one, $C^{k k^{\prime}}$, intended for the other type. Let the menu favoured by type- $k$ agents be denoted by $\mathcal{C}^{k} \equiv\left(C^{k k}, C^{k k^{\prime}}\right)$. Effort is private information at the voting stage - no signals have yet been observed - and so the menu $\mathcal{C}^{k}$ must induce type $k^{\prime}$ to self-select. ${ }^{8,9}$

Let

$$
v^{k}(C) \equiv \sum_{j} \sum_{i} f_{j}^{k} \pi_{i}^{k} u\left(c_{i j}\right)
$$

denote the expected utility of consumption for a type- $k$ agent in a contract $C$. Given beliefs $\theta=\left(\theta^{1}, \theta^{2}\right)$ concerning the composition of the population, the optimal menu from the point of view of a type- $k$ agent is then a solution to

$$
\max _{\mathcal{C}^{k}} v^{k}\left(C^{k k}\right) \quad \text { s.t. } \quad(4) \quad \text { and } \quad v^{k^{\prime}}\left(C^{k k^{\prime}}\right)-v^{k^{\prime}}\left(C^{k k}\right) \geq 0 .{ }^{10}
$$

Denote the solution by $\mathcal{C}^{k}(\theta)=\left(C^{k k}(\theta), C^{k k^{\prime}}(\theta)\right)$. Two observations can immediately be made about $\mathcal{C}^{k}(\theta)$. First, pooling is not optimal; this follows immediately from the fact that the two types have different probability distributions over earnings/signal combinations. Second, the self-selection constraint is binding at the optimum: if it were not, then type $k^{\prime}$ would be offered zero consumption. Moreover, type $k^{\prime}$ is always offered full insurance. The menu $\mathcal{C}^{k}(\theta)$ then induces expected consumption utilities $v^{k k}(\theta) \equiv v^{k}\left(C^{k k}(\theta)\right)$ and $v^{k k^{\prime}}(\theta) \equiv v^{k^{\prime}}\left(C^{k k^{\prime}}(\theta)\right)$ (the first superscript refers to the type casting the vote and the second superscript to the type affected).

Any type's ideal menu always provide her type with a higher continuation utility than that provided to the other type. The proof is omitted. ${ }^{11}$

Lemma $1 v^{k k}(\theta)>v^{k k^{\prime}}(\theta)$ for any distribution of types $\theta$ and $k=1,2$.

In general, voters will trade off consumption risk for higher expected consumption, but as the fraction of any type approaches unity, the contract that agents of a certain type would choose for themselves approaches full insurance: the only reason why type- $k$ agents would choose, for themselves, a contract with

\footnotetext{
${ }^{8}$ The own self-selection constraint can easily be shown never to bind.

${ }^{9}$ We abstract from interim participation constraints, i.e. from the possibility that agents may opt out of the social insurance scheme if it leaves them with a lower expected consumption utility than if they remain fully uninsured. The presence of an interim participation constraint, if anything, weakens the redistributive power of social insurance, and hence the pressure toward conformity that majority voting can exercise on the minority. Nevertheless, it can be shown that results analogous to those we obtain for the no opt-out case (Propositions 1-3 below) apply to a scenario where individuals can opt out.

${ }^{10}$ The problem is one of provision of insurance under adverse selection with two risk groups. Indeed, Problem (6) can be viewed as characterizing a particular constrained Pareto-efficient allocation: the allocation that maximizes the utility for type $k$.

${ }^{11}$ Type- $k$ agents offer type $k^{\prime}$-agents full insurance, and offer themselves an incomplete insurance contract which assigns high consumption-levels to earnings/signal combinations that are relatively likely for type $k$. The result then follows immediately from the fact that the self-selection constraint on type $k^{\prime}$ is binding.
} 
consumption risk is that doing so may relax the self-selection constraint for the other type and thus allow them to obtain a higher expected level of consumption; but, as $\theta^{k}$ approaches unity, the gain to doing so vanishes. The contract $C^{k k}$ therefore converges to a constant consumption level, which, by the budget constraint, must equal $\bar{w}^{k}$. Note, however, that a positive level of consumption need only be offered to agents who send type- $k$ compatible signals, i.e. signals in the set $S^{k}$. For any other signal it is optimal for $k$-type agents to assign zero consumption.

\subsection{Comparing Signal Structures}

The redistributive power of a social insurance system - and hence the pressure toward conformity that majority voting can generate - hinges on what information is available about private choices. To study the role of information, we need a way of characterizing the informativeness of a certain signal structure. Two such measures are relevant for our purposes: one measures how often an agent's action is completely revealed; the second is a more general measure of informativeness.

Let $\phi_{k^{\prime}}^{k}(\sigma) \equiv \sum_{s_{j} \in S^{k}} f_{j}^{k^{\prime}}$, for $k^{\prime} \neq k$. In words, $\phi_{k^{\prime}}^{k}(\sigma)$ is the probability that a type- $k^{\prime}$ agent sends a signal that is also sent with positive probability by a type- $k$ agent. Since an agent is revealed as being of type $k^{\prime}$ if she sends a signal that is never sent by a type- $k$ agent, we say that the signal structure $\sigma$ is at least as revealing as $\hat{\sigma}$ for type $k^{\prime}$ if $\phi_{k^{\prime}}^{k}(\sigma) \leq \phi_{k^{\prime}}^{k}(\hat{\sigma})$.

To see the relevance of this definition for our analysis, consider the contract that type $k$ agents prefer for themselves, $C^{k k}(\theta)$. As noted earlier, this always optimally involves zero consumption on all signals not compatible with effort $h^{k}$. It then also follows (from the binding self-selection constraint) that the expected consumption utility of the other type will depend on how revealing $\sigma$ is; specifically, $v^{k k^{\prime}}(\theta)$ approaches

$$
\bar{v}^{k k^{\prime}}(\sigma) \equiv \phi_{k^{\prime}}^{k}(\sigma) u\left(\bar{w}^{k}\right)+\left(1-\phi_{k^{\prime}}^{k}(\sigma)\right) u(0)
$$

as $\theta^{k}$ approaches unity. Moreover, since type $k^{\prime}$ is always offered full insurance, the utility level $\bar{v}^{k k^{\prime}}(\sigma)$ also pins down a limiting constant consumption level for type $k^{\prime}$, which depends inversely on how often $k^{\prime}$ is revealed, i.e. on the probability $1-\phi_{k^{\prime}}^{k}(\sigma)$. When $\theta^{k}$ is exactly unity, the own contract $C^{k k}$ is undefined for signals not compatible with effort $h^{k}$; neither is the contract $C^{k k^{\prime}}$ defined. It is still, however, useful to assume that the agents vote for a social insurance system that is the limit of $C^{k k}(\theta)$ as $\theta^{k}$ approaches unity.

The "at least as revealing as" criterion fails to rank signal structures that never unambiguously reveal actions. A more general (and well-known) measure of informativeness is the Blackwell criterion:

Definition 1 The signal structure $\sigma=\{S, f\}$ is (Blackwell) more informative than $\hat{\sigma}=\{\hat{S}, \hat{f}\}$ if there exists a Markov matrix $\left[\beta_{\hat{\jmath} j}\right]$ such that, for each $s_{\hat{\jmath}} \in \hat{S}$, we have $\hat{f}_{\hat{\jmath}}^{k}=\sum_{s_{j} \in S} \beta_{\hat{\jmath} j} f_{j}^{k}$, for $k=1,2$. 
If $\sigma$ is more informative than $\hat{\sigma}$, it is also at least as revealing as $\hat{\sigma}$ for both types, although the converse is not necessarily the case. As a standard result it can then be shown that the more (Blackwell) informative is the signal structure, the higher is the expected consumption utility that the type selecting the menu can secure for themselves. Formally including the signal structure as an argument in the indirect utility, we have

LEMMA 2 If $\sigma$ is more informative than $\hat{\sigma}$, then $v^{k k}(\theta ; \sigma) \geq v^{k k}(\theta ; \hat{\sigma})$ for any distribution of types $\theta$ and $k=1,2$.

\subsection{Equilibria and Information}

We next characterize the set of equilibria of the game, conditional on a signal structure, $\sigma$. The main results can be summarized as follows. If $\sigma$ reveals a low-effort agent with sufficient accuracy, then there exists a pure-strategy high-effort equilibrium with full insurance (corresponding to the fully efficient outcome). Furthermore, there may exist, conditional on any signal structure, mixed-strategy equilibria in which a majority of agents choose high effort, although there will also always exist a pure-strategy low-effort equilibrium. In general, the more informative is $\sigma$, the more effort can, in general, be supported.

Recall the timing of choices: agents first choose education efforts, possibly by randomizing; they then vote over social insurance schemes; finally, earnings and signals are realized and taxes and transfers are carried out. A behavioural strategy for an agent thus consists of a probability distribution $\theta=\left(\theta^{1}, \theta^{2}\right)$ over low and high effort, together with a rule describing how to vote depending on her effort choice (and beliefs). The relevant equilibrium concept is Nash equilibrium (since there are no proper subgames): in equilibrium each agent holds correct beliefs about the actions of the other agents and chooses a behavioural strategy that is a best response to the other agents' behavioural strategies. To refine the equilibrium set, ruling out potentially "unreasonable" limiting equilibria, we shall also apply a simple perfection argument: each agent is required to choose each effort level with at least probability $\varepsilon$; we then let $\varepsilon$ approach zero. ${ }^{12} \mathrm{We}$ can start by noting the following:

Proposition 1 Conditional on any signal structure $\sigma$ :

1. There exists a perfect pure-strategy Nash equilibrium where all agents choose low effort, $\theta^{1}=1$.

2. There does not exist any mixed-strategy Nash equilibrium with $\theta^{2} \in(0,1 / 2)$.

Part 1 says that a pure-strategy low-effort equilibrium always exists; hence if any effort is to obtain in equilibrium, there have to be multiple equilibria. Part

\footnotetext{
${ }^{12}$ This corresponds to the notion of an " $\varepsilon$-constrained" equilibrium (Fudenberg and Tirole, 1989), except that we only require the agents to randomize over effort levels, not at the voting stage. Note, however, that in this application, the perfection argument does not in fact rule out any equilibria; it does, however, pin down the specific contracts in any pure-strategy equilibrium.
} 
2 rules out equilibria where a strict minority choose high effort. The reason is simple: if the low-effort agents are in majority, the resulting social insurance system will provide a higher expected consumption utility to low-effort agents than to high-effort agents. Anticipating this, no one would rationally choose the more costly high effort at the ex-ante stage.

We are left with the possibility of either a mixed-strategy equilibrium or a pure-strategy high-effort equilibrium. For the agents to randomize over effort levels, they must be indifferent between $h^{1}$ and $h^{2}$. This is compatible with $\theta^{2}>1 / 2$, since the social insurance system selected by the high-effort majority then gives a larger expected consumption utility to high-effort agents than to low-effort agents: $v^{22}(\theta)>v^{21}(\theta)$ (see Lemma 1). The following result is then immediate:

Proposition 2 If, for some $\theta^{2} \in(1 / 2,1), v^{22}(\theta)-v^{21}(\theta)=g^{2}-g^{1}$, then there exists a perfect symmetric mixed-strategy Nash equilibrium, where each agent chooses high effort with probability $\theta^{2}$.

To understand this result, note that if all agents choose high effort with probability $\theta^{2}$, then, ex post, the social insurance system $\mathcal{C}^{2}(\theta)$ is implemented through the political process. Rationally anticipating this, each agent is indifferent between high and low effort at the ex-ante stage, and hence optimally randomizes. Finally, since the agents are randomizing over efforts, the equilibrium is also perfect.

It may also be possible to support pure-strategy high-effort equilibria - the fully efficient outcome; however, this requires that a low-effort agent be revealed sufficiently often. Note the intuition behind this result: if all agents choose the high effort, they will vote, at the ex-post stage, for full insurance over all signals that are compatible with high effort. However, they can credibly vote for a very low consumption level over all signals that are not compatible with high effort. This discourages an agent from choosing low effort if the probability of sending such signals is sufficiently high. Also note that, if such an equilibrium exists, it is also perfect.

Proposition 3 There exists, conditional on $\sigma$, a pure-strategy Nash equilibrium in which all agents choose high effort with probability one if and only if

$$
\left(u\left(\bar{w}^{2}\right)-u(0)\right)\left(1-\phi_{1}^{2}(\sigma)\right) \geq g^{2}-g^{1} .
$$

If the above inequality is strict, the equilibrium is also perfect.

Thus, given a generic signal structure $\sigma$, three types of symmetric equilibria may obtain: a low-effort equilibrium, a mixed-strategy equilibrium where individuals choose high effort with a probability greater than $1 / 2$, and a higheffort equilibrium. The symmetric high-effort equilibrium requires that loweffort agents be sometimes fully revealed.

Intuitively, the maximum amount of effort (measured as the fraction of agents choosing high effort) which can be supported relates to the informativeness of the signal structure. Suppose that the more informative is $\sigma$, the 


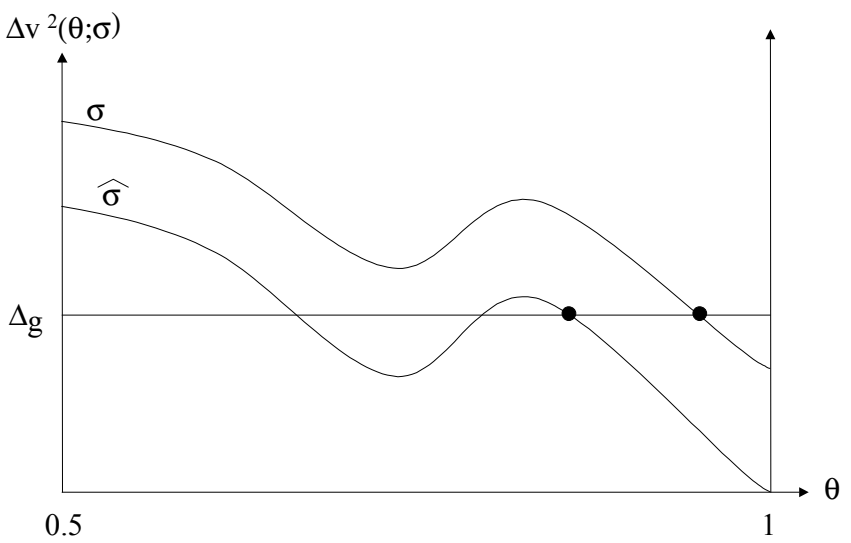

Figure 2: How more information can affect equilibrium effort.

larger is the difference in the consumption utilities of the type choosing the menu and of the other type, i.e. suppose that $v^{k k}(\theta)-v^{k k^{\prime}}(\theta)$ is larger (for each $k$ and $\theta$ ) the more informative is $\sigma{ }^{13}$ In that case, we can show that the intuition is correct. To see this, consider two signal structures, $\sigma$ and $\hat{\sigma}$, where $\sigma$ is more informative than $\hat{\sigma}$. Recall that $\sigma$ is then also at least as revealing (for each type) as $\hat{\sigma}$. It then immediately follows from Proposition 3 that, if $\hat{\sigma}$ supports a pure-strategy high-effort equilibrium, $\sigma$ does so too. On the other hand, if $\hat{\sigma}$ does not support any high effort at all, then $\sigma$ cannot support less effort. Finally, suppose that $\hat{\sigma}$ supports a mixed-strategy equilibrium with $\theta^{2}>1 / 2$. Then, as shown in Figure 2 (where $\Delta v^{2}(\theta ; \sigma) \equiv v^{22}(\theta ; \sigma)-v^{21}(\theta ; \sigma)$, and $\left.\Delta g \equiv g^{2}-g^{1}\right), \sigma$ will either support a mixed-strategy equilibrium with a larger fraction of high-effort agents or a pure-strategy high-effort equilibrium.

The above results point to a second key point: just like public information is valuable when commitment to policy is feasible, public information is valuable when policy is selected through a political process after private actions have been carried out. The reason is, however, quite different: information has a positive value because it enables the majority to divert more resources in its own direction; this generates a tendency to conformity with the result that agents may be able to coordinate on a reasonably good outcome, despite the lack of policy commitment. This, e.g., reverses a result described by Konrad (2001) for a scenario very similar to our second application, where redistributive taxes are chosen by a utilitarian social planner after the individuals invest in human capital. His analysis shows that some incentives for investment can be preserved if the returns from the human capital investment are not fully observed by the planner.

${ }^{13}$ This is suggested, but not implied, by Lemma 2 . 


\section{Discussion}

The preceding analysis has shown that renegotiation of policy through a political process can help overcome the problems that arise from a lack of policy commitment, even in economies with ex-ante identical agents. This is because, when there is interim heterogeneity, the political process may allow a majority to divert resources in their direction. This makes it attractive to belong to the interim majority, or, stated differently, it generates a tendency to conformity.

The mechanism we have characterized relies centrally on the quasi-dictatorial nature of majority voting, whereby the minority's preferences are given no weight in collective choices. This is the very feature that makes majority voting a potentially inefficient procedure in a static context; in the scenario we have described, this flaw becomes a virtue. The enforcement role played by majority rule in the presence of policy-renegotiation bears some conceptual similarity to the idea of social norms promoting conformism (Akerlof, 1980); what makes it distinct is that with voting-based renegotiation the pressure to conform to the choices of others does not come from an exogenous norm, but is channelled through the collective social contract.

Throughout our discussion we have stressed the idea that politics can matter in dynamic environments even in the absence of population heterogeneity. This does not mean that our findings are only relevant in situations where individuals are identical in all respects. In practice, individuals are different and have different policy preferences; yet, if individuals have reasonably similar preferences along a certain policy dimension, it may well be legitimate to examine policy choices in that dimension while abstracting from heterogeneity along other dimensions. What our analysis has shown is that politics remain relevant even in such cases.

The argument has been formalized by focusing on binary first-period choices; this modelling strategy makes majority voting robust and consistent with a broad class of political processes. With more than two possible voter types, existence of a voting equilibrium under direct democracy may be a problem; however, many other models of political competition, such as, e.g., citizen-candidate models, have better equilibrium existence properties and could be used in these cases. Even with more than two available choices, however, a political process will generate an incentive towards conformity whenever the political power of a relatively large group exceeds its relative size. ${ }^{14}$ This is indeed a feature of most

\footnotetext{
${ }^{14}$ Given any general political choice rule that is consistent with majority voting - in situations where only two types of voters exist - and no matter how many interim voter types there can be, if signals are sufficiently informative there will exist an efficient pure-strategy equilibrium: when all individuals select the efficient level of effort, a hypothetical deviation by one individual would only give rise to two voter types (no matter how many types could conceivably arise); thus, if the political mechanism employed is such that the will of $N-1$ voters always prevails over that of a single voter of a different type (at least when $N$ is large enough), and if the signal structure is sufficiently revealing, then deviations can be prevented by the ex-post redistributive instruments that would be supported in an ex-post political equilibrium, as described in Proposition 3. Also note that, by the same arguments that were used to establish Proposition 3, it can be shown that, when more than two choices are possible in
} 
models of political choice mechanism, with majority voting of course being the extreme example. ${ }^{15}$

Our second application has also highlighted the key supporting role of information: the more observable private choices are, the easier it is for the majority to extract surplus from the minority by conditioning taxes and transfers on any observable characteristics that are correlated with private actions. This has two implications. First, if individuals can costlessly choose amongst a set of feasible information structures at the ex-ante stage, they will have a strategic incentive to select one that is revealing as discussed. ${ }^{16}$ Second, at the ex-ante stage, individuals may unanimously choose to adopt an informative signal structure even if it is not revealing and even if it is costly. More generally, an improvement in the economy's information technology, in the sense of an expansion of the set of available signal structures, will if anything enhance welfare (measured as the common ex-ante level of expected utility). ${ }^{17}$

\section{Colophon}

The first draft of this paper was prepared in May of 2000.

We are grateful to seminar participants at Warwick University and at the University of St. Andrews for comments and suggestions. Two anonymous referees also provided helpful comments.

Correspondence should be addressed to Carlo Perroni, Department of Economics, Warwick University, Coventry, CV4 7AL, UK, c.perroni@warwick.ac.uk

\section{Appendix}

Proof of Lemma 2. The argument follows Grossman and Hart (1983). The solution to problem (6) given $\hat{\sigma}$ involves one contract, $\hat{C}^{k k}$, which provides consumption $\hat{c}_{i \hat{\jmath}}^{k k}$ on $\left(w_{i}, s_{\hat{\jmath}}\right)$, and a second contract, $\hat{C}^{k k^{\prime}}$, which offers constant consumption, $\bar{c}$. Suppose then that, when $\sigma$ is available, type $k$ votes for a menu $\left(C^{k k}, C^{k k^{\prime}}\right)$, where, conditional on $\left(w_{i}, s_{j}\right), C^{k k}$ offers consumption $\hat{c}_{i \hat{\jmath}}^{k k}$ with probability $\beta_{\hat{\jmath} j}$, and $C^{k k^{\prime}}$ offers a constant consumption $\bar{c}$ on all earnings

the first period - and in the absence of interim participation constraints - for any possible investment or effort choice there exists a signal structure such that that particular choice can be supported as an equilibrium pure strategy.

${ }^{15}$ Note that the probabilistic voting political model described at the end of Section 2 is the other extreme example where the property fails to hold: in that case the equilibrium policy maximized the sum of utilities, thus implicitly giving equal weight to all agents.

${ }^{16}$ In the context of education choices, a revealing information structure could consist of a system of public examinations of academic attainment.

${ }^{17}$ It can be shown that the availability of costly signal structures may enable "reasonably good" equilibria to be supported even if the choice of a signal structure is made ex post: an ex-post majority may find it optimal to incur the cost in order to improve their ability to redistribute resources through policy. In this scenario, however, there would no longer be a presumption that an improvement in the information technology should be (weakly) welfare improving. 
and signals. If a type- $l$ agent, $l=1,2$, picks $C^{k k}$, she obtains $\hat{c}_{i \hat{\jmath}}^{k k}$ with probability $\pi_{i}^{l} \sum_{s_{j} \in S} \beta_{\hat{\jmath} j} f_{j}^{l}=\pi_{i}^{l} \hat{f}_{\hat{\jmath}}^{l}$, while if she picks $C^{k k^{\prime}}$ she receives the constant consumption $\bar{c}$. Thus, by using a stochastic contract, the allocation chosen by type $k$ given $\hat{\sigma}$ can be perfectly replicated when the more informative signals structure $\sigma$ is in place. Consequently, $v^{k}(\theta ; \sigma) \geq v^{k}(\theta ; \hat{\sigma})$. The outcome can, however, be further improved. $C^{k k}$ maps each realization $\left(w_{i}, s_{j}\right)$ into a lottery with expected utility $\sum_{s_{\hat{\jmath}} \in \hat{S}} \beta_{\hat{\jmath} j} u\left(\hat{c}_{i \hat{\jmath}}^{k k}\right)$; then, if $C^{k k}$ is replaced with a non-stochastic contract $\widetilde{C}^{k k}$ that offers the same utility on each realization, i.e. $u\left(\tilde{c}_{i j}^{k k}\right)=\sum_{s_{\hat{\jmath}} \in \hat{S}} \beta_{\hat{\jmath} j} u\left(\hat{c}_{i \hat{\jmath}}^{k k}\right)$ for all $i, j$, type $k$ 's utility is unchanged (while keeping the self-selection constraint satisfied), but the expected consumption is less; this relaxes the budget constraint, thus allowing further improvement. From this, we can also conclude that stochastic contracts are never optimal.

Proof of Proposition 1. Part (1). Suppose all agents choose $h^{1}$. Holding correct beliefs, each agent then optimally votes for the menu $\mathcal{C}^{1}(1,0)$ and obtains the expected payoff $u\left(\bar{w}^{1}\right)-g^{1}$. An agent who deviates and chooses $h^{2}$ obtains a constant consumption $\bar{c}^{12} \leq \bar{w}^{1}$ (see the discussion in Section 3.3); moreover $g^{2}>g^{1}$; hence the agent is better off not deviating. Thus there is a Nash equilibrium where all agents choose $h^{1}$ with probability one and vote for $\mathcal{C}^{1}(1,0)$. This equilibrium is also perfect. Suppose that each agent chooses $h^{1}$ with the largest possible probability, $\theta^{1}=1-\varepsilon$. A type- $k$ agent then optimally votes for $\mathcal{C}^{k}(1-\varepsilon, \varepsilon)$. Since $\varepsilon$ is small, low-effort agents are in majority; by Lemma 1 they vote for a social insurance system such that $v^{11}(\theta)>v^{12}(\theta)$. Since high effort is also more costly, $g^{2}>g^{1}$ it is indeed a best response for each agent to minimize the probability of choosing $h^{2}$. In other words, the described choices constitute a Nash equilibrium in the perturbed economy; moreover, as $\varepsilon$ approaches zero, this Nash equilibrium approaches the symmetric low-effort equilibrium in the original economy.

Part (2). Suppose the agents randomize over effort levels with $\theta^{1} \in(0.5,1)$. In the interim $\mathcal{C}^{1}(\theta)$ is then the winning menu. The expected consumption utility for a low-effort agent then exceeds that for a high-effort agent, $v^{11}(\theta)>v^{12}(\theta)$ (Lemma 1). But, then since effort is costly, $g^{2}>g^{1}$, the expected lifetime utility of a high effort agent is lower than that of low effort agent, contradicting that the agents optimally randomize over effort levels.

Proof of Proposition 3. Suppose all agents choose $h^{2}$ with probability one. Each agent then optimally votes for $\mathcal{C}^{2}(0,1)$, which generates ex-ante utility $u\left(\bar{w}^{2}\right)-g^{2}$ for each agent. An agent who instead deviates and chooses $h^{1}$ obtains expected consumption utility $\bar{v}^{21}(\sigma)$ defined in (7). Straightforward calculations then show that an agent is better off not deviating if and only if (8) holds. To see that this equilibrium is also "perfect", suppose all agents choose $h^{2}$ with maximum probability, $\theta^{2}=1-\varepsilon$. Each type- $k$ agent then votes for $\mathcal{C}^{k}(\varepsilon, 1-\varepsilon)$. If $(8)$ is satisfied with inequality, then by continuity, $v^{22}(\varepsilon, 1-\varepsilon)-v^{21}(\varepsilon, 1-\varepsilon)>g^{2}-g^{1}$; hence it is optimal for each agent to maximize the probability of choosing $h^{2}$. Moreover, as $\varepsilon$ approaches zero, this Nash equilibrium in the perturbed economy approaches a pure high-effort Nash 
equilibrium in the original economy.

\section{References}

Akerlof, G.A. (1980) 'A theory of social custom, of which unemployment may be one consequence.' Quarterly Journal of Economics 94, 749-775.

Boadway, R., and M. Keen (1998) 'Evasion and time consistency in the taxation of capital income.' International Economic Review 39, 461-476.

Boadway, R., N. Marceau, and M. Marchand (1996a) 'Investment in education and the time inconsistency of redistributive tax policy.' Economica 63, 171-189.

Boadway, R., N. Marceau, and M. Marchand (1996b) 'Time-consistent criminal sanctions.' Public Finance 51, 149-165.

Dixit, A., and J. Londregan (1998) 'Ideology, tactics, and efficiency in redistributive politics.' Quarterly Journal of Economics 113, 497-529.

Fischer, S. (1980) 'Dynamic inconsistency, cooperation, and the benevolent dissembling government.' Journal of Economic Dynamics and Control 2, 93-107.

Fudenberg, D., and J. Tirole (1989) Game theory, MIT Press.

Fudenberg, D., and J. Tirole (1990) 'Moral hazard and renegotiation in agency contracts.' Econometrica 58, 1279-1319.

Gradstein, M. (1999a) 'An Economic Rationale for Public Education: The Value of Commitment.' CESifo working paper No. 209.

Gradstein, M. (1999b) 'Optimal taxation and fiscal constitutions.' Journal of Public Economics 72, 471-485.

Grossman, S.J., and O. Hart (1983) 'An analysis of the principal-agent problem.' Econometrica 51, 7-45.

Kydland, F.E., and E.C. Prescott (1977) 'Rules rather than discretion: The inconsistency of optimal plans.' Journal of Political Economy 85, 473491.

Konrad, K.A. (2001) 'Privacy, time consistent optimal labor income taxation and education policy.' Journal of Public Economics 79, 503-519.

Lindbeck, A., and J. Weibull (1987) 'Balanced-budget redistribution and the outcome of political competition.' Public Choice 52, 273-297.

Persson, T., and G. Tabellini (1994) 'Representative democracy and capital taxation.' Journal of Public Economics 55, 53-70.

Persson, T., and G. Tabellini (2000) Political economics: Explaining economic policy. MIT Press, Cambridge, Massachusetts. 